\title{
Impact of the North Atlantic Warming Hole on Sensible Weather $\mathscr{A}$
}

\author{
Melissa Gervais \\ Department of Meteorology and Atmospheric Science, and The Institute for CyberScience, The Pennsylvania \\ State University, University Park, Pennsylvania, and Lamont-Doherty Earth Observatory, \\ Columbia University, New York, New York \\ JEFFREY SHAMAN \\ Department of Environmental Health Sciences, Columbia University, New York, New York \\ YOCHANAN KUSHNIR \\ Lamont-Doherty Earth Observatory, Columbia University, New York, New York
}

(Manuscript received 20 August 2019, in final form 17 February 2020)

\begin{abstract}
In future climate projections there is a notable lack of warming in the North Atlantic subpolar gyre, known as the North Atlantic warming hole (NAWH). In a set of large-ensemble atmospheric simulations with the Community Earth System Model, the NAWH was previously shown to contribute to the projected poleward shift and eastward elongation of the North Atlantic jet. The current study investigates the impact of the warming hole on sensible weather, particularly over Europe, using the same simulations. North Atlantic jet regimes are classified within the model simulations by applying self-organizing maps analysis to winter daily wind speeds on the dynamic tropopause. The NAWH is found to increase the prevalence of jet regimes with stronger and more-poleward-shifted jets. A previously identified transient eddy-mean response to the NAWH that leads to a downstream enhancement of wind speeds is found to be dependent on the jet regime. These localized regime-specific changes vary by latitude and strength, combining to form the broad increase in seasonal-mean wind speeds over Eurasia. Impacts on surface temperature and precipitation within the various North Atlantic jet regimes are also investigated. A large decrease in surface temperature over Eurasia is found to be associated with the NAWH in regimes where air masses are advected eastward over the subpolar gyre prior to reaching Eurasia. Precipitation is found to be locally suppressed over the warming hole region and increased directly downstream. The impact of this downstream response on coastal European precipitation is dependent on the strength of the NAWH.
\end{abstract}

\section{Introduction}

The global oceans are generally expected to warm under increasing greenhouse gases (GHGs). One notable exception is the North Atlantic warming hole (NAWH), a region in the subpolar gyre south of Greenland where CMIP5 models project that SSTs will warm at a much slower rate (Gervais et al. 2018; Drijfhout et al. 2012; Menary and Wood 2018). The NAWH is found in the majority of the CMIP5 models; however, there is a wide

\footnotetext{
Supplemental information related to this paper is available at the Journals Online website: https://doi.org/10.1175/JCLI-D-190636.s1.
}

Corresponding author: Melissa Gervais,mmg62@psu.edu range in the location and strength of the NAWH developments across the suite of CMIP5 (Menary and Wood 2018). Changes in ocean heat transport are important for the formation of the NAWH (Winton et al. 2013; Menary and Wood 2018; Gervais et al. 2018) and studies have related it to the slowdown of the Atlantic meridional overturning circulation (AMOC) (Rahmstorf et al. 2015; Drijfhout et al. 2012; Gervais et al. 2018; Menary and Wood 2018). In particular, Menary and Wood (2018) found that a reduction in deep water formation, followed by a slowdown of the AMOC, precedes the formation of the NAWH in CMIP5 models. Focusing on more local processes within the Community Earth System Model (CESM), Gervais et al. (2018) demonstrated the importance of increased freshwater fluxes from the Arctic into the North Atlantic in producing the NAWH 
through their effect on Labrador Sea deep convection and subsequent impacts on ocean heat transport within the subpolar gyre.

The location of the NAWH in the subpolar gyre provides a wide region of reduced SST warming and acts to enhance the existing SST gradient across the boundary between the subpolar and subtropical gyres. Many observational, theoretical, and modeling studies have been conducted to understand how such midlatitude SST anomalies can impact atmospheric circulation. These studies find two dominant response mechanisms, a baroclinic direct linear response (Hoskins and Karoly 1981; Hendon and Hartmann 1982) and a nonlinear equivalent barotropic response forced by transient eddies (Palmer and Sun 1985; Ting and Peng 1995; Peng and Whitaker 1999; Peng and Robinson 2001; Hall et al. 2001; Deser et al. 2004; Kushnir et al. 2002). In general, the latter nonlinear equivalent barotropic response resembles atmospheric internal variability, which for the North Atlantic is dominated by the North Atlantic Oscillation (Deser et al. 2004). SST gradients associated with midlatitude SST anomalies lead to increased baroclinicity, which can provide enhanced wave activity for the North Atlantic storm track (Nakamura et al. 2004; Brayshaw et al. 2011; Inatsu et al. 2003; Wilson et al. 2009). The atmospheric response to midlatitude SST anomalies is strongly dependent on the strength and polarity of SST anomalies (Hall et al. 2001; Magnusdottir et al. 2004), the background atmospheric circulation (Ting and Peng 1995; Peng and Whitaker 1999; Hall et al. 2001), and the location of the SST gradient relative to the mean jet (Brayshaw et al. 2008; Nakamura et al. 2004). When North Atlantic SST gradients are located poleward of the subtropical jet, as is the case for the NAWH, the eddy-driven jet tends to be amplified, resulting in a net poleward shift of the jet (Brayshaw et al. 2008).

Several studies have examined the impact of SST anomalies within the North Atlantic similar to the NAWH. In a freshwater hosing experiment with resulting subpolar gyre cooling, Woollings et al. (2012) saw an enhancement of the North Atlantic storm track. Gervais et al. (2019) examined the impact of the NAWH through a series of prescribed SST and sea ice modeling studies and found that the NAWH leads to a poleward shift and eastward extension of the North Atlantic jet. Other studies with prescribed SSTs in the North Atlantic have shown a more limited response (Ciasto et al. 2016; Harvey et al. 2015; Magnusdottir et al. 2004), although this may be the result of the location of the imposed SST differences relative to the background model SST gradients (Gervais et al. 2019).

The winter seasonal-mean atmospheric response found in Gervais et al. (2019) consists of a direct response consistent with the atmospheric response to a low-level cooling as described in Hoskins and Karoly (1981). This results in a negative temperature anomaly that weakens with height, a local high pressure anomaly downstream, and a baroclinic response in the geopotential height fields. More important than the local linear response is a transient eddy-mean feedback response. The enhanced gradient in SST results in increased baroclinic eddy activity. An E-vector analysis reveals that this baroclinic eddy energy propagates vertically and horizontally, ultimately enhancing the North Atlantic jet and extending it eastward. This study will employ the same model experiments as Gervais et al. (2019) but will focus on the impact of the NAWH on atmospheric variability and sensible weather (e.g., the daily variability of precipitation and surface temperature) instead of on the seasonal-mean atmospheric state.

Over the North Atlantic, the dominant mode of variability is the North Atlantic Oscillation (NAO) whose positive phase is characterized by a poleward shift and eastward elongation of the North Atlantic jet and associated enhancement of the Icelandic low and the subtropical high. The enhanced westerly flow in the positive phase of the NAO is associated with higher land surface temperatures over northern Europe and across Asia (Hurrell et al. 2003). It is also associated with a shift of the North Atlantic storm track to the northeast, typically resulting in enhanced precipitation from Iceland to Scandinavia and drier conditions in south and central Europe down to the Mediterranean (Hurrell 1995; Dai et al. 1997). Several studies have examined the potential coupled relationship between the NAO and the Atlantic multidecadal variability (AMV), demonstrating that the ocean can play a role in impacting atmospheric variability on longer time scales (Delworth and Zeng 2016; Peings et al. 2016). In a study on decadal variability of the North Atlantic jet, Woollings et al. (2018) found that during periods where the North Atlantic jet is stronger, it also exhibits less variability. Given the socioeconomic implications of variability in North Atlantic circulation on European, North American, and North African weather, it is important to understand the processes that are responsible for producing this variability and how it may change in the future.

In the current study, we will investigate how the atmospheric response to the NAWH is manifested in terms of daily atmospheric variability. We use self-organizing maps (SOMs) to identify North Atlantic jet regimes and their associated impacts on sensible weather over the European continent. We introduce a novel application of the SOM method to examine differences between simulations that are the result of changes in North Atlantic jet regimes themselves versus changes in the 
frequency of their occurrence. Results from this study demonstrate how mean changes in atmospheric circulation are manifested as changes in the dominant patterns of jet variability in the North Atlantic. This has implications for future changes in European and North African weather.

\section{Data and methods}

\section{a. Modeling experiments}

This study employs a series of experiments conducted using the Community Earth System Model 1.2 (CESM), described in further detail within Gervais et al. (2019). The model includes an active atmosphere model, the Community Atmosphere Model 5.3 (CAM5), at a horizontal resolution of $0.9^{\circ}$ latitude $\times 1.25^{\circ}$ longitude and 30 levels in the vertical as well as an active land model, the Community Land Model 4.5, at the same horizontal resolution. The ocean and sea ice components of the model are prescribed, with an alteration to include variable sea ice thickness instead of the default 2-m assumption. These prescribed SSTs and sea ice cover are provided at daily temporal resolution on a tripole grid with a horizontal resolution of approximately $1^{\circ}$. The radiative forcing imposed for all experiments is the CMIP5 RCP8.5 forcing scenario. Further details regarding the CESM model can be found in Hurrell et al. (2013). A special issue collection of the Journal of Climate has also been established (http://journals.ametsoc.org/topic/ccsm4-cesm1), which can provide additional information regarding the representation of climate variability in the model.

These experiments were configured so that they remain as close as possible to the fully coupled Community Earth System Model Large Ensemble (LENS) experiments conducted by Kay et al. (2015) but are able to isolate the impact of the NAWH on the atmosphere through the use of prescribed SST and sea ice cover. A total of seven experiments each consisting of 25 ensemble members were conducted for different time periods and prescribed SSTs. Experiments were run over three time periods, 2006-19, 2046-59, and 2086-99, of which the first 4 years are discarded prior to analysis. Three types of experiments are conducted that represent different variations in the strength of the NAWH: "control" where SSTs are identical to the fully coupled simulation, "filled" where the NAWH is reduced, and "deepened" where the NAWH is enhanced. Each ensemble member for each experiment was initialized as a hybrid run branched from the corresponding ensemble member in the LENS experiment (Kay et al. 2015). Details regarding the production of these prescribed SST and sea
TABLE 1. List of experiments conducted and their specifications (from Gervais et al. 2019).

\begin{tabular}{lcc}
\hline \hline \multicolumn{1}{c}{ Expt } & Time interval & SST modification \\
\hline CNTRL10 & $2006-19$ & - \\
CNTRL50 & $2046-59$ & - \\
CNTRL90 & $2086-99$ & - \\
1KFill50 & $2046-59$ & $+1-\mathrm{K}$ fill patch \\
2XDeep50 & $2046-59$ & $-1-\mathrm{K}$ fill patch \\
2KFill90 & $2086-99$ & $+2-\mathrm{K}$ fill patch \\
2XDeep90 & $2086-99$ & $-2-\mathrm{K}$ fill patch \\
\hline
\end{tabular}

ice cover will be discussed below and a summary of these simulations can be found in Table 1.

For the control simulations, sea ice cover and SSTs were provided from the corresponding LENS experiments over the corresponding time interval. As a result, each individual ensemble member in the control experiments is an extension of the corresponding ensemble member in the LENS experiment but with SSTs and sea ice cover prescribed from the fully coupled simulation instead of using a fully coupled configuration. These experiments will be called CNTRL10, CNTRL50, and CNTRL90 to denote runs over the 2006-19, 2046-59, and 2086-99 time intervals. Although the SSTs and sea ice cover in the control experiments are identical to the fully coupled experiments, the lack of coupling can still produce biases. Gervais et al. (2019) showed that there are mean biases in the turbulent heat fluxes on the order of $10 \mathrm{~W} \mathrm{~m}^{-2}$ in the CNTRL simulations, as compared to the LENS experiments; however, the impact of the $\mathrm{NAWH}$ on turbulent heat fluxes is similar between the two simulations.

The goal of the filled (deepened) experiments is to remove (enhance) the warming hole, while retaining the general increase in SSTs associated with greenhouse gas forcing. The average increase in North Atlantic SSTs between the 2050s (2090s) and the 2010s is roughly $1 \mathrm{~K}$ $(2 \mathrm{~K})$, and so any region that experiences an SST increase of less than $1 \mathrm{~K}(2 \mathrm{~K})$ is considered part of the NAWH. Two seasonally varying fill patches were produced, one for the 2050s and one for the 2090s, such that adding these fill patches to the control SSTs results in an approximately equal increase in SSTs over the North Atlantic by $1 \mathrm{~K}$ for the 2050 s and $2 \mathrm{~K}$ for the 2090 s. To produce the $1-\mathrm{K}$ fill patch for the $2050 \mathrm{~s}$, the decadal ensemble-average SSTs for each day of the year are computed for the 2050-59 and 2010-19 decades; wherever the difference is less than the $1-\mathrm{K}$ threshold within the NAWH region (green lines in Fig. 1) the fill patch is defined as the absolute value of the difference between the two decades. At the edges of the NAWH, the fill patch was smoothed such that it decreases linearly to 0 away from the NAWH region boundaries over the 

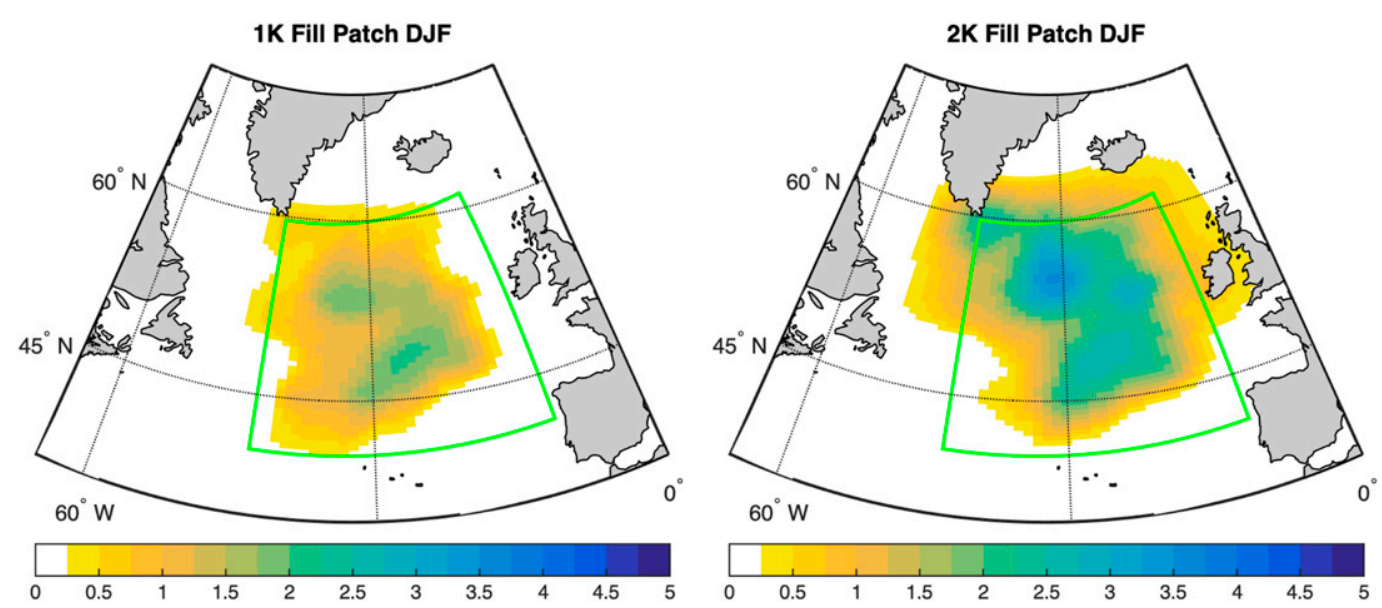

FIG. 1. DJF average of experiment seasonally varying fill patches, where (left) the 1-K fill patch is used for the 2050s and (right) the 2-K fill patch is used for the 2090s. The green box denotes the fill patch region and patches with positive values at this edge are linearly interpolated to zero away from the boundary to produce smooth edges.

course of five grid boxes to avoid artificial temperature gradients. The 2090s patch was produced using the same procedure but with a threshold of $2 \mathrm{~K}$ and smoothing the edges over the course of 10 grid points. These daily fill patches exhibit a large seasonality with greater magnitudes in the winter/spring seasons when the NAWH is deepest and smaller magnitudes in the fall/summer seasons. The December-February (DJF) average of the fill patch values are shown in Fig. 1.

The final set of experiments was conducted by adding or subtracting these fill patches to the control run SSTs. The "filled" experiments, hereinafter referred to as 1KFill50 and 2KFill90, consist of adding the seasonally varying fill patch to each day of data in the 2046-59 and 2086-99 control runs respectively. The "deepened" experiments, hereinafter referred to as 2XDeep50 and 2XDeep90, consist of subtracting the seasonally varying fill patch from each day of data in the 2046-59 and 2086-99 control runs respectively. A cross section of SSTs through the NAWH for all experiments confirms that the filled experiments have SSTs that follow the CNTRL10 simulations but with a net increase of SSTs in the NAWH region of roughly $1 \mathrm{~K}(2 \mathrm{~K})$ for the 2050 s (2090s) as desired (Gervais et al. 2019). Results in this study will focus on the DJF season during which Gervais et al. (2019) showed the largest impact on the North Atlantic jet by the NAWH.

\section{b. Self-organizing maps}

We are interested in understanding how the NAWH impacts daily atmospheric variability. One classical method for doing this is using synoptic typing, whereby atmospheric data are manually classified into different synoptic patterns. Such an approach is not feasible for this study given the large volume of data to classify. Atmospheric variability is also commonly identified through the use of empirical orthogonal functions (EOFs) that decompose the variability into a set of orthogonal basis vectors. This method is used to identify the NAO as the dominant mode of atmospheric variability in the North Atlantic (Hurrell et al. 2003). One limitation of EOFs arises from the requirement that all basis patterns be orthogonal, which can lead to nonphysical basis patterns or blending of underlying patterns (Reusch et al. 2005; Liu et al. 2006). Furthermore, this method assumes that the data being provided are stationary. Given the experimental design with multiple time periods and experiments, this criterion is certainly violated.

In this study, we instead use self-organizing maps (SOMs), a machine learning method, to characterize atmospheric variability. This method identifies a set of archetypal patterns and classifies the data in a similar manner to traditional synoptic typing; however, with the use of machine learning this can be conducted on a large volume of data, such as the large ensemble used in this study. In comparison to a method like EOF analysis, SOMs do not make assumptions about orthogonality and consequently can produce patterns that are more physical. There are also no underlying assumptions within the SOM method about stationarity of the data (which could be problematic for a study with multiple time periods and experiments). Much like the real atmosphere, the SOM method assumes that the data exist on a continuum instead of in distinct categories. The archetypal patterns identified are then organized such that more similar patterns are closer together in the map. Software for conducting the SOM analysis was obtained at http://www.cis.hut.fi/research/som-research/ 
(Vesanto et al. 2000). For further information regarding the SOM algorithm, see Kohonen (2001).

Within the field of atmospheric science, the SOM method has been used for a variety of applications, for example to construct synoptic climatologies (Hewitson and Crane 2002), to identify conditions related to extreme events (E. Cassano et al. 2006; Cavazos 2000), to validate model variability (Schuenemann and Cassano 2009), and to characterize future changes in atmospheric variability (Schuenemann and Cassano 2010; J. Cassano et al. 2006; Gervais et al. 2016). Previous work examining North Atlantic variability in particular has demonstrated the utility of the SOM method in capturing shifts in the centers of actions of the NAO teleconnection (Johnson et al. 2008; Reusch et al. 2007), nonlinear aspects of variability (Reusch et al. 2007), and intermediate patterns (Reusch et al. 2007).

SOMs are a type of neural network that are trained through an iterative process to produce a predetermined number of archetypal patterns called SOM nodes. For this study, an SOM is trained on daily wind speed on the dynamic tropopause (DT Wind), where the dynamic tropopause is defined as the 2 potential vorticity unit (PVU; $1 \mathrm{PVU}=10^{-6} \mathrm{~K} \mathrm{~kg}^{-1} \mathrm{~m}^{2} \mathrm{~s}^{-1}$ ) surface. This field is chosen because the North Atlantic jet is of great importance for sensible weather in this region and using the dynamic tropopause values of wind speed allows us to track the jet even if the troposphere height increases with global climate change. Output from all experiments in DJF within the region $30^{\circ}-80^{\circ} \mathrm{N}, 70^{\circ} \mathrm{W}-70^{\circ} \mathrm{E}$ is used to train the SOM. In the final SOM, each map node will be a DT Wind map that is representative of daily DT Wind patterns that occur in the simulations.

The SOM procedure begins with initialization of the SOM nodes, in this case with random values. This initial SOM is then updated through repeated exposure to the input data that allows the map to learn to represent the data's distribution. The map is trained for a number of training periods ( 2 in this case) and each data vector is provided a number of times (10 in this case) during each training period. In this study, the SOM is trained using data from all seven experiments in order to capture all patterns of variability within the set of simulations. One other logical choice would have been to train the SOM with only the CNTRL10 data; however, if new patterns emerge by the end of the century these might not be well represented by the SOM if they were not included in the training process. There are a total of 157500 data vectors (90 days per season $\times$ 10 years per ensemble member $\times 25$ ensemble members per experiment $\times 7$ experiments). This results in a total of 1575000 training steps $t$ as each data vector is provided 10 times.
At each $t$ training step, the map is provided with an input data vector $\mathbf{x}(t)$ and is compared to each of the SOM nodes $m_{i}$, where $i=1,2,3, \ldots, 12$ for a $3 \times 4$ SOM. A best-match unit $c$ is identified as the corresponding map node $m_{c}$ with the smallest Euclidean distance to the input data vector. Each of the $m_{i}$ SOM nodes are then modified according to the following update function:

$$
m_{i}(t+1)=m_{i}(t)+\alpha(t) h_{c i}(t)\left[\mathbf{x}(t)-m_{i}(t)\right],
$$

where the learning-rate parameter $\alpha$ is a decreasing function with $t$ that determines how the SOM nodes will be altered; in this case, the inverse function begins at 0.5 and 0.1 for the first and second training periods respectively. The neighborhood function $h_{c i}$ determines which SOM nodes will be impacted. This neighborhood function is important for organizing the SOM as it alters nodes closest to the best match unit more than those farther away, ultimately resulting in an SOM that has similar patterns clustered together. The Epanechikov neighborhood function was chosen as it has been shown in idealized test to outperform other neighborhood functions (Liu et al. 2006). It is defined as follows:

$$
h_{c i}=\max \left[0,1-d^{2} / r(t)^{2}\right],
$$

where $d$ is the distance between a given map node $i$ and the best-match unit $c$ on the map grid-for example, adjacent SOM nodes $(1,1)$ and $(1,2)$ have a $d=1$ and distant map nodes $(1,4)$ and $(3,4)$ have a $d=5$-and $r$ is the radius of influence, the maximum distance from the best match unit where the map is updated. It is good practice to have a radius of influence equal to the map diameter at the beginning of the first training (5 in this case) and a smaller radius of influence ( 2 in this case) for the second training. Throughout the training processes the value of $r$ decreases linearly with the training step $t$.

There are three diagnostics that can be used to assess if the SOM produced is well constructed: the quantization error (QE), topological error (TE), and Sammon map. QE is a measure of how similar the SOM nodes are to the input data vectors and is defined as $\mathrm{QE}=$ $\sum\left\|x_{i}-m_{c}\right\|$. TE is a measure of how well organized the SOM is, defined as the percentage of data vectors whose next best match unit is not a neighboring unit. The QE decreases throughout the training time and the TE typically decreases initially and begins to increase if the SOM becomes overtrained. A well-constructed SOM should have a balance of low QE and low TE. The Sammon map is produced through a nonlinear mapping from higher to lower dimension and is used to visualize the organization and relative distances between SOM 
nodes (Sammon 1969). A well-constructed SOM should also have a flat Sammon map.

In the SOM method there are a number of subjective choices of tunable parameters (e.g., $\alpha, h$, SOM size, and training length). The SOM size is particularly important because a small SOM size can lead to the blending of patterns that have physical relevance whereas larger SOM sizes produce patterns with more detail but can become unmanageable and more difficult to interpret. Multiple SOM sizes were tested and a final choice of $3 \times$ 4 SOM size was made as larger SOMs were found to contain duplicate patterns deemed unnecessary and smaller SOMs lead to the merging of patterns. This SOM size balances the need to represent the distribution of atmospheric variability being studied and the convenience of a smaller more easily interpreted SOM. The SOM presented here is well constructed, with a balance of low topological and quantization errors, as well as a flat Sammon map. For well-constructed SOM nodes, the choice of the remaining parameters is typically less important.

Once the final SOM has been trained each input data vector is assigned a best match unit, the map node with the smallest Euclidean distance to the input data. This provides the opportunity to conduct various additional forms of analysis. The patterns of variability associated with each SOM node can be examined by computing the SOM node composites $S_{i}$, the averages of all days for which each SOM node $i$ is the best match unit, where $i=1,2,3, \ldots, 12$ for a $3 \times 4$ SOM. The SOM node composites computed using the DT wind output for all experiments are very similar to the SOM nodes themselves. These composites can also be conducted with additional variables to provide a more complete view of the atmospheric circulation and sensible weather associated with each node. The best match unit frequency of occurrence (BMUF or $f_{i}$ ) can also be defined for each SOM node as the percentage of input vectors for which it is the best match unit. This provides information about how prevalent each of these SOM nodes are.

Although the SOM itself is trained with data from all experiments, there may be differences between experiments in how often the nodes occur and in the average pattern associated with that map node. To assess this, the composites and BMUF analysis can also be conducted separately for each of the experiments. Differences in these map node composites $\Delta S_{i}$ and frequency of occurrences $\Delta f_{i}$ between experiments can then be computed. When these differences are conducted for conducted for the filled minus control or filled minus deepened experiments, this shows the impact of NAWH or the twice deepened NAWH, respectively.
Provided this information about changes in SOM node composite and frequency, we can then determine the relative contributions of changes in pattern versus changes in frequency on the total difference between experiments. We begin by noting that we can approximately reconstruct the mean of a given field as the sum over all SOM nodes of the frequency of occurrence of each node $f_{i}$ multiplied by its SOM node composite $S_{i}$. We will define BMUFs $\left(f_{1 i}\right.$ and $\left.f_{2 i}\right)$ and SOM node composites $\left(S_{1 i}\right.$ and $\left.S_{2 i}\right)$ computed separately for two different experiments with subscripts 1 and 2 denoting the experiments and $i$ denoting the node. By extension, we will define the SOM reconstructed difference in means between the two experiments as

$$
\Delta(f S)=\sum_{i=1}^{n} f_{1 i} S_{1 i}-\sum_{i=1}^{n} f_{2 i} S_{2 i}
$$

where $n$ is the total number of SOM nodes.

We can further decompose $\Delta(f S)$ into the role of differences in frequency $\Delta f S_{\text {avg }}$ and the role of differences in SOM node composite $f_{\text {avg }} \Delta S$ as follows:

$$
\Delta(f S)=\Delta f S_{\mathrm{avg}}+f_{\mathrm{avg}} \Delta S,
$$

where

$$
\begin{gathered}
\Delta f S_{\mathrm{avg}}=\sum_{i=1}^{n}\left(f_{1 i}-f_{2 i}\right) \frac{S_{1 i}+S_{2 i}}{2}, \\
f_{\mathrm{avg}} \Delta S=\sum_{i=1}^{n} \frac{f_{1 i}+f_{2 i}}{2}\left(S_{1 i}-S_{2 i}\right) .
\end{gathered}
$$

This decomposition will allow us to assess the relative roles of differences in SOM node frequency of occurrence versus SOM node composite.

\section{Results}

The SOM method is used to classify DT wind variability in our experiments into a series of SOM node patterns, which we will also refer to as regimes. To understand the circulation patterns associated with these SOM nodes, we examine composites of DT Wind, SLP, and 500-hPa geopotential height (Z500) for all days associated with each map node (Fig. 2). Within the bottom row of the SOM, the jet is in a more northerly position near $45^{\circ} \mathrm{N}$, transitioning from having a maximum farther east $\left(5^{\circ} \mathrm{W}\right)$ to farther west $\left(50^{\circ} \mathrm{W}\right)$ as you move from left $(3,1)$ to right $(3,4)$ (Fig. 2). Each of these patterns is associated with a well-developed Icelandic low and a subtropical high that shifts east-west with the jet maximum. Moving up along the left edge of the map [from pattern $(3,1)$ to $(1,1)]$ there is a shift toward a more 
1

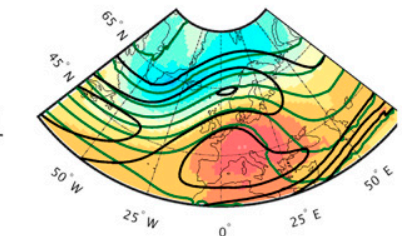

2

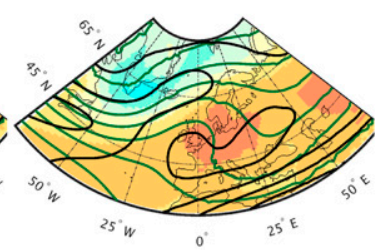

2

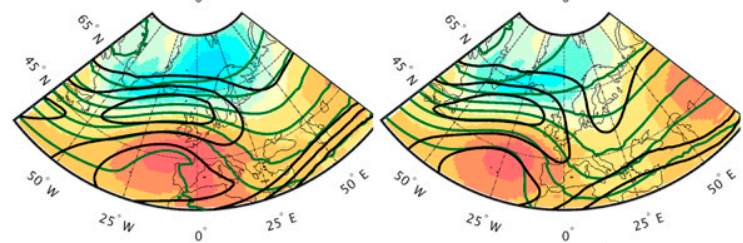

3
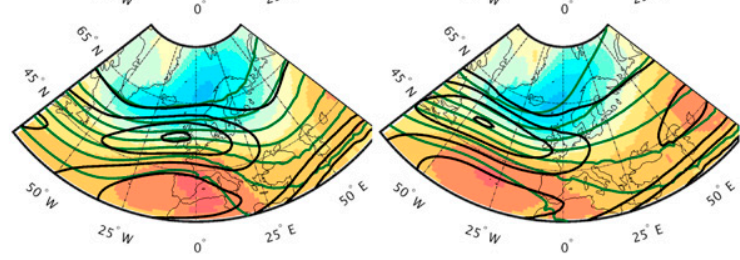

3
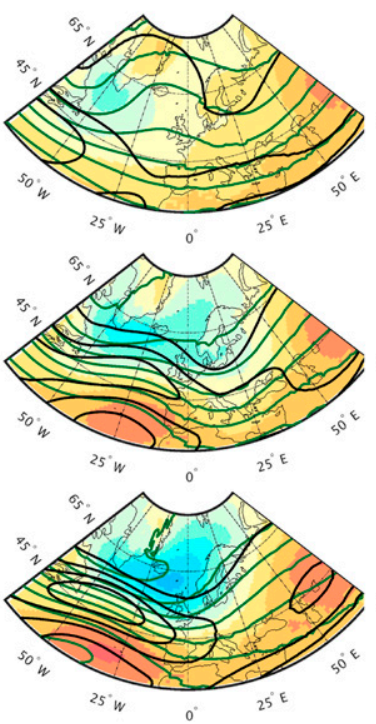

4
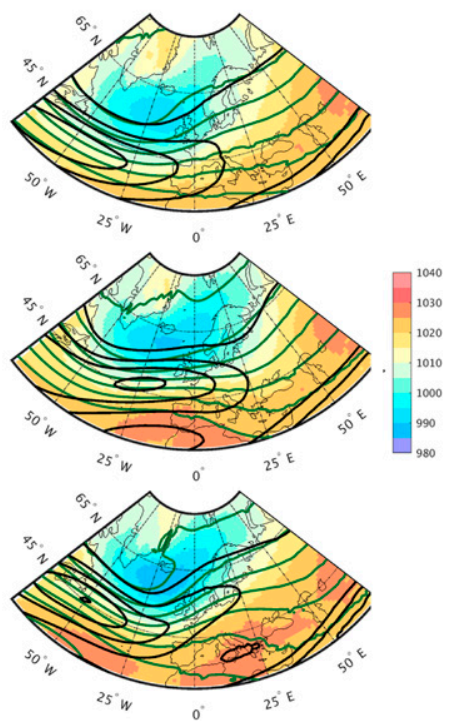

FIG. 2. DJF SOM node composites for all experiments showing wind speed on the dynamic tropopause (black contours every $10 \mathrm{~m} \mathrm{~s}^{-1}$ beginning at $20 \mathrm{~m} \mathrm{~s}^{-1}$ ), sea level pressure (hPa; color), and 500-hPa geopotential height (green contours every $100 \mathrm{~m}$ ).

southwest-northeast-oriented jet that is strongest west of $50^{\circ} \mathrm{W}$. This is associated with a strong subtropical high centered over Europe. In patterns $(1,2)$ and $(1,3)$ we see a reduction in the extent of the jet and some ridging in the Z500 field. Pattern $(1,3)$ has a particularly strong ridge in Z500, lower pressures over the Labrador Sea, and no discernible subtropical high. Moving to the topright corner, there is a strengthening of the North Atlantic jet in the more southern position around $40^{\circ} \mathrm{N}$, accompanied by a more expansive Icelandic low and again no discernible subtropical high $(1,3)$.

The SOM node BMUFs provide information about how often each of these SOM node patterns occur. We can examine the distribution of BMUF for each experiment separately. For example, in Fig. 3a we can see the distribution of BMUF for the CNTRL10 simulation. There is variability within the SOM in terms of how often each of these SOM nodes is the best match unit, with node $(1,1)$ being the most frequent at $10.2 \%$ and node $(2,4)$ the least frequent at $6.4 \%$. For all experiments, each of the SOM nodes occurs, highlighting the fact that the data are best described by a continuum of patterns.

We next examine the impact of these jet regimes on sensible weather over Europe, in particular on precipitation and surface air temperature (TS). In general, these jet regimes are associated with precipitation and TS anomalies through similar mechanisms as the NAO (Hurrell et al. 2003). The North Atlantic jet and associated SLP gradient transports warmer air where the jet reaches the European coast and continuing into interior Europe. There is also enhanced precipitation where the North Atlantic jet, and the related North Atlantic storm track, reaches the European coast. This results in dipoles in TS and precipitation anomalies dependent on the position of the North Atlantic jet in a given regime (Fig. 4).

We are interested here in understanding the impact of the NAWH on these jet regimes and associated sensible weather. To address this, we note that there are two central ways in which differences in atmospheric variability can be represented in an SOM analysis. There may be differences between experiments in how often individual SOM nodes occur. This can be assessed as the differences between the BMUFs computed for two experiments. There may also be differences in the daily patterns associated with each of the SOM nodes. This can be assessed by examining differences in the SOM node composites computed for two experiments.

With the set of experiments conducted here, we can examine changes in frequency of SOM node occurrence due to the NAWH. Figures $3 \mathrm{a}-\mathrm{c}$ show the progression of the total SOM BMUF from CNTRL10, 1KFill50, and 2KFill90 where the decades are increasing but there is no development of the NAWH. Here we see a general shift in BMUF with a reduction in occurrence of patterns in the upper left corner of the map with weak to moderately strong poleward-shifted jets [nodes $(1,1)$, $(1,2),(2,1)$, and $(2,2)]$ and an increase in occurrence of those on the right side of the map with stronger and 

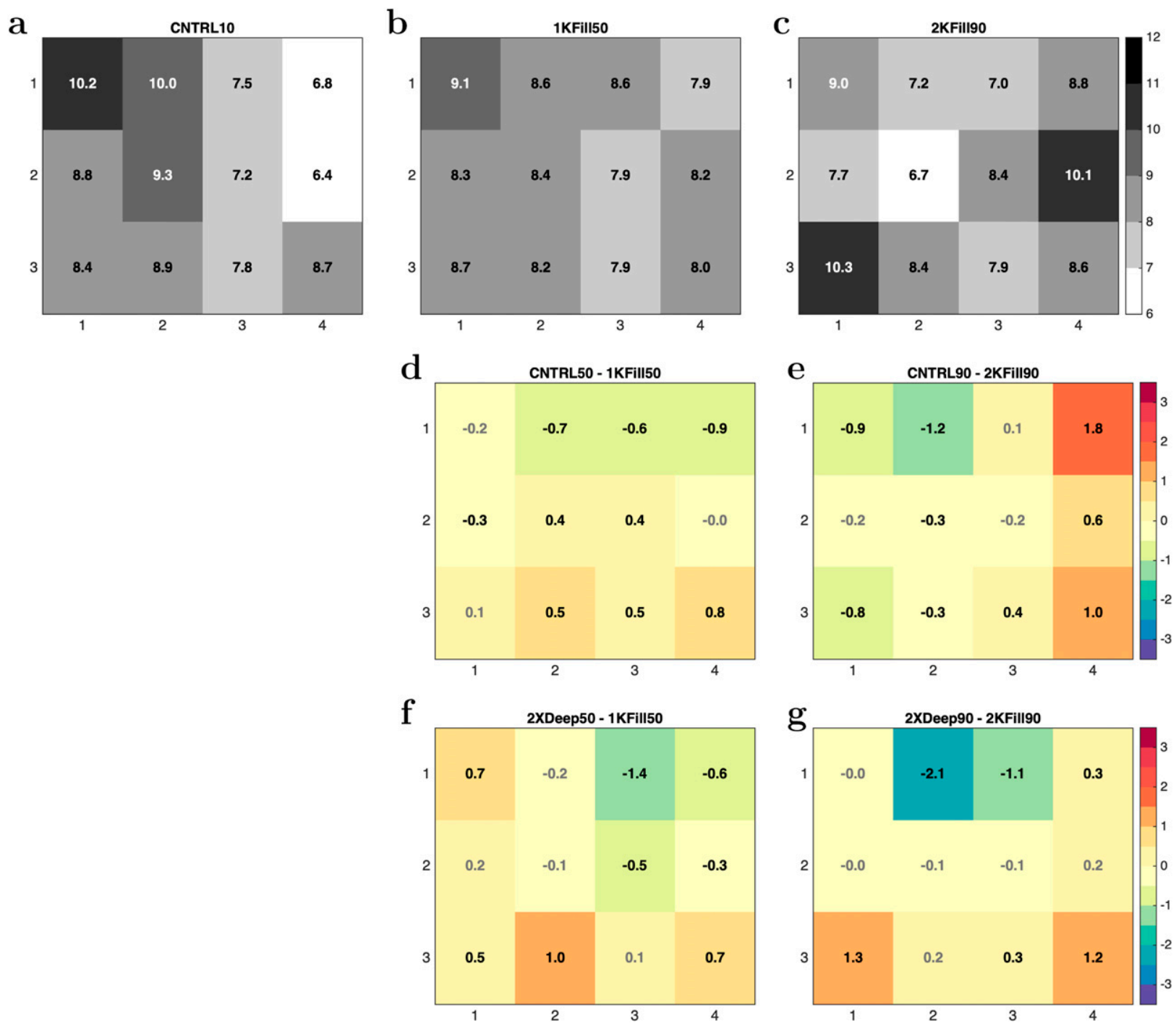

FIG. 3. DJF frequency map for (a) CNTRL10, (b) 1KFill50, and (c) 2KFill90 with shading and numbers representing the frequency of occurrence for each SOM node. Also shown are differences in frequency maps for (d) CNTRL50 - 1KFill50, (e) CNTRL90 - 2KFill90, (f) 2XDeep50 - 1KFill50, and (g) 2XDeep90 - 2KFill90 with numbers and colors representing the difference in frequency of occurrence between the two experiments and significant differences in boldface, computed as discussed in the methods section.

more-equatorward-shifted jets [nodes $(1,4),(2,3)$, and $(2,4)]$, as well as an increase in node $(3,1)$ with a stronger more-poleward jet. This can be thought of as the impact of global warming without the NAWH on the SOM node distribution.

To assess the impact of the NAWH on SOM node frequencies for each of the 2050s and 2090s decades, the differences in SOM node BMUF, $\Delta f_{i}$, are also computed between the control or deepened experiments relative to the filled experiments. Significance testing of these differences is conducted using a permutation test. For each SOM node, the best match unit data from both experiments are pooled and then randomly separated into two new sets of sample data. The difference in SOM node BMUF is then computed between these two sets of resampled data. This procedure is repeated 1000 times and the resulting SOM node BMUF differences are used to construct a null distribution. If the actual BMUF difference between the two experiments lies outside the 5th and 95th percentiles of this null distribution, their difference is deemed significant. It is worth noting that each input data vector must be assigned to a map node and so a decrease in BMUF in one map node must imply an increase in frequency in others.

The impact of the NAWH on SOM node frequencies is generally smaller than for global warming without the NAWH (Figs. 3a-c), but many of the changes are significant (Figs. 3d-g). In the BMUF difference between 
1

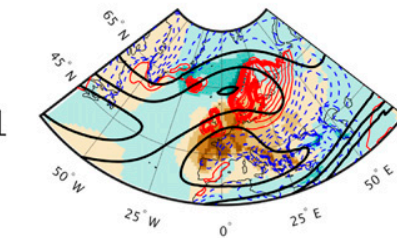

2

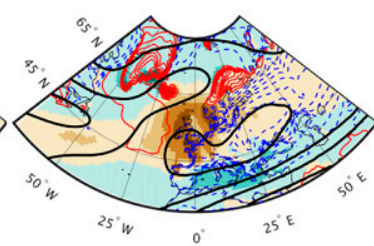

3
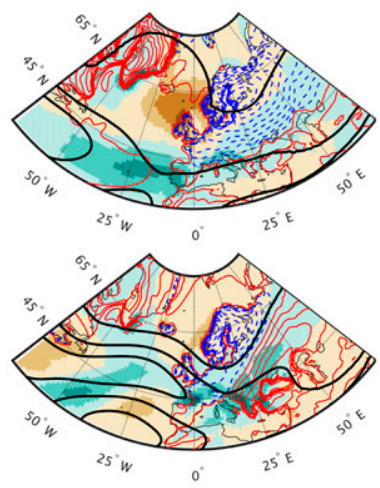

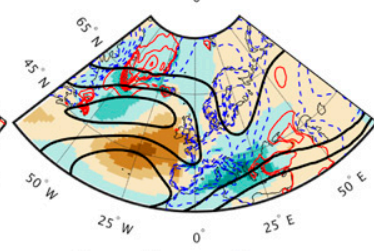

2
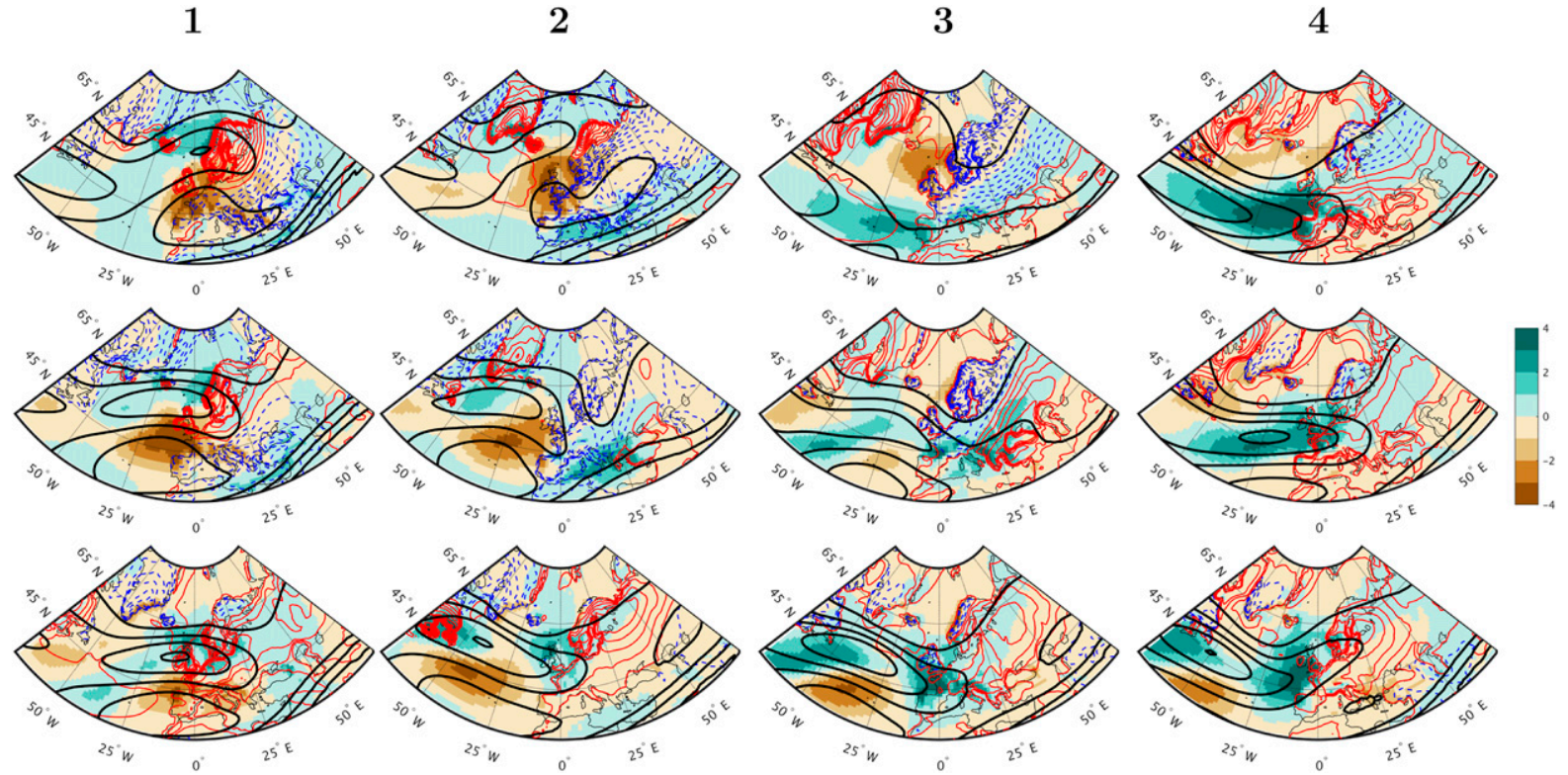

3

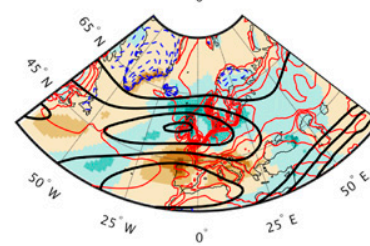

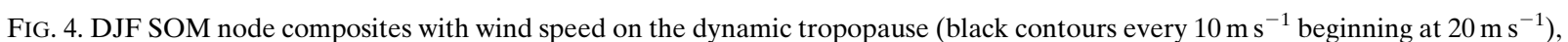
precipitation anomalies ( $\mathrm{mm}_{\text {day }}{ }^{-1}$; color), and surface temperature (red contours, positive; blue contours, negative; plotted every $0.5^{\circ} \mathrm{C}$ ). Here anomalies are relative to the average over all DJF simulation data (all nodes and experiments).

CNTRL50 and 1KFill50 the NAWH is generally responsible for decreasing select patterns in the top row in favor of those in the bottom row (Fig. 3d) with stronger and more poleward jets (Fig. 2). As the warming hole deepens there is a further increase in nodes $(3,2)$ and $(3,4)$, with some new differences such as an increase in node $(1,1)$ and decrease in node $(2,3)$ (Fig. 3f). Differences in BMUF with NAWH development in the 2090s are more complex, with the CNTRL90 - 2KFill90 BMUF differences resembling the general global climate difference with increases in frequencies on the right side of the map and decreases in those on the left side. In particular there is a large increase in the frequency of occurrence of node $(1,4)$ that has a strong North Atlantic jet located in a more equatorward position (Fig. 2), as was found in the seasonal-mean difference between these experiments (Gervais et al. 2019). However, as the NAWH strengthens there are larger decreases in nodes $(1,2)$ and $(1,3)$ and increases in nodes $(3,1)$ and $(3,4)$, more in line with the response to the NAWH found in the 2050s.

Changes in the daily fields associated with each of the SOM nodes are another important source of changes in daily variability. This can be shown through differences in SOM node composites between experiments $\left(\Delta S_{i}\right)$. Figure 5 shows the differences in SOM node composites between the CNTRL90 and 2KFill90 experiments for DT Wind. To assess how the transient eddy forced response to the NAWH is related to these changes in the
North Atlantic jet we also examine differences in the lower-troposphere eddy heat transport $\overline{v^{\prime} T^{\prime}}$ at $850 \mathrm{hPa}$ $\left(\overline{v^{\prime} T_{850}^{\prime}}\right)$. Here the primed values refer to a 3-8-day highpass filter applied to the temperature $T$ and meridional wind component $v$ prior to the calculation of $\overline{v^{\prime} T_{850}^{\prime}}$. Positive values of $\overline{v^{\prime} T_{850}^{\prime}}$ represent upward propagation of eddy activity from eddies tilted westward with height.

Gervais et al. (2019) showed that in the seasonal mean, there is an increase in North Atlantic storm activity due to the enhanced baroclinic zone provided by the NAWH. Furthermore, this enhanced transient-eddy activity propagates upward and downstream leading to a strengthening of the North Atlantic jet (Gervais et al. 2019). Our results expand upon this work and demonstrate how this mechanism occurs in different jet regimes. In all jet regimes, the difference in SOM nodes

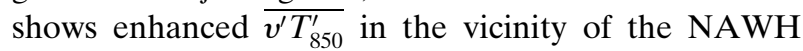
(Fig. 5). Although the source of surface baroclinicity is stationary, being tied to the NAWH, the magnitude of $\overline{v^{\prime} T_{850}^{\prime}}$ and its impact on the North Atlantic jet depends on the jet regime. In general, there are extensions of the North Atlantic jet due to the NAWH; however, they occur at different locations depending on where the jet terminates in a given regime. The differences in SOM node composites in the 2050s have enhanced DT Wind in the North Atlantic jet confined to the North Atlantic (see Figs. S1 and S2 in the online supplemental material). As the NAWH strengthens in the 2090s there are also differences farther downstream over the European continent (Fig. 5; see also Fig. S3). 
1

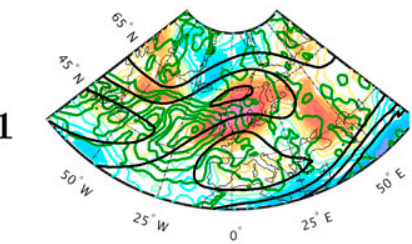

2

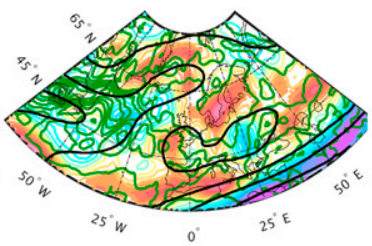

3

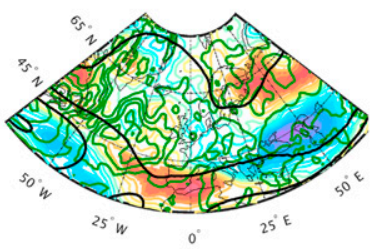

4

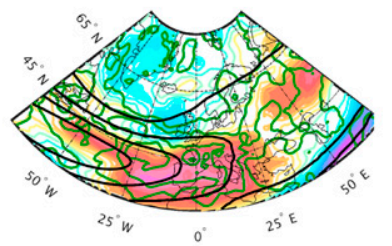

2
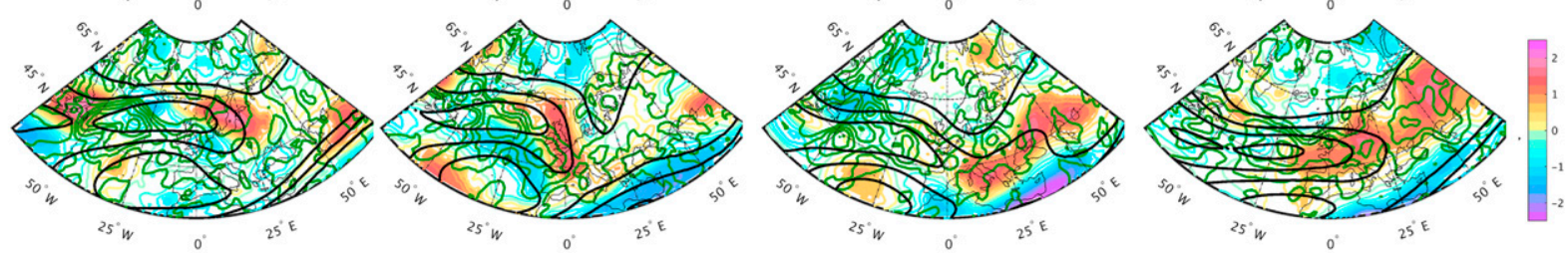

3
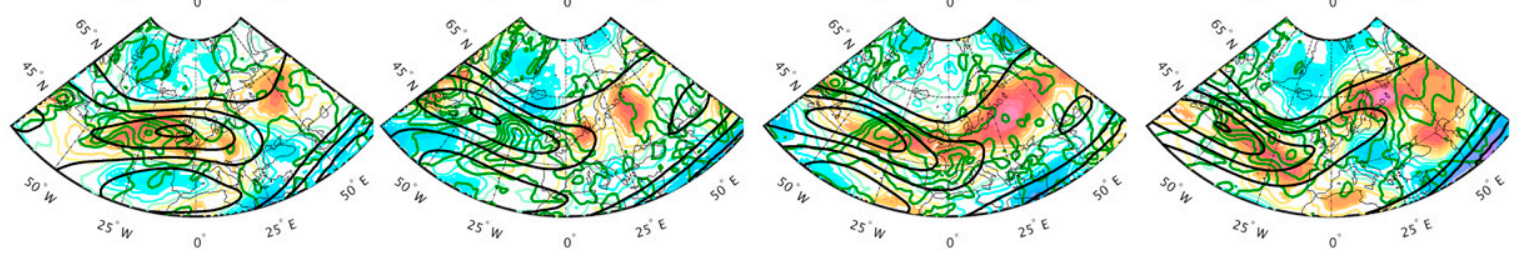

FIG. 5. DJF SOM node composite differences between the CNTRL90 and 2KFill90 experiments for dynamic tropopause wind speed $\left(\mathrm{m} \mathrm{s}^{-1}\right.$; color filled when significant at $95 \%$ confidence level using a two-sided Student's $t$ test) and $\overline{v^{\prime}} T_{850}^{\prime}$ (green contours every $0.5 \mathrm{~m}^{2} \mathrm{~s}^{-2}$ beginning at $0.5 \mathrm{~m}^{2} \mathrm{~s}^{-2}$ ). The average dynamic tropopause wind speeds for the two experiments are also shown (black contours every $10 \mathrm{~m} \mathrm{~s}^{-1}$ beginning at $20 \mathrm{~m} \mathrm{~s}^{-1}$ ).

Processes that occur only for certain regimes are also elucidated by the differences in SOM node composites between experiments. For example, as the NAWH deepens and in the later decade, node $(2,1)$ displays anomalous wind speeds on the dynamic tropopause that exhibit an enhanced ridge over the NAWH and trough over southern Europe (Fig. 5). This type of response bears a strong resemblance to enhanced Rossby wave breaking at this location. Node $(1,4)$, which exhibited an unusual increase in frequency of occurrence in the CNTRL90 - 2KFill90 BMUF differences, also exhibits an abnormal change in the SOM node composite between these experiments, with a large increase in wind speed within the southerly positioned jet (Fig. 5). Similar to the BMUF differences, this would result in an apparent equatorward shift of the North Atlantic jet in the mean as was shown in Gervais et al. (2019). This equatorward jet enhancement for node $(1,4)$ only occurs in the CNTRL90 - 2KFill90 difference.

The SOM analysis was conducted on the DT Wind variable and captures North Atlantic jet variability (Fig. 2). SOM node differences in TS indicate the important role that the NAWH plays in impacting the overlying atmosphere. Examining the CNTRL90 2KFill90 differences in particular, there is a large decrease in TS directly over the imposed SST differences that is present in all SOM nodes. The strength of this impact is dependent on NAWH strength, with TS differences ranging from $4^{\circ}$ to $6^{\circ} \mathrm{C}$ depending on the experiment (not shown). Associated with these TS differences, there are positive SLP differences over the NAWH in most of the SOM nodes, consistent with the linear response to the NAWH. The SLP differences are typically more variable over this region between nodes than the TS.

There are also downstream impacts over Europe that differ depending on the SOM node (Fig. 6). For the large number of SOM node patterns in locations where warm surface temperatures are typically transported by enhanced westerlies (Fig. 4), we see a reduction in temperatures owing to the NAWH (Fig. 6). This response is consistent with the relative cooling of air masses as they are transported over the NAWH and subsequently over Europe. There are also some positive TS impacts over Scandinavia, particularly during the early time period (not shown). These are typically associated with SLP differences that induce a more southwesterly component to the flow.

Significant differences in SOM node precipitation also occur between different experiments. The dominant feature is a general suppression of precipitation in conjunction with the NAWH and smaller increases in precipitation in the surrounding regions (Fig. 7). This is consistent with an increase in stability owing to the decrease in TS over the NAWH shown in Fig. 6. There are larger enhancements in precipitation associated with the NAWH for some SOM nodes, in particular nodes 
1

1

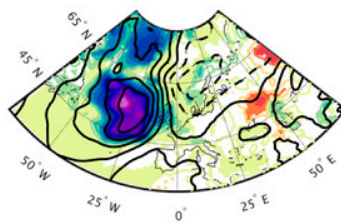

2

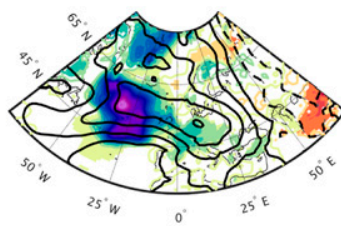

3

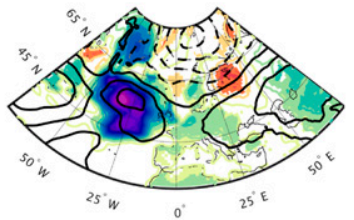

2
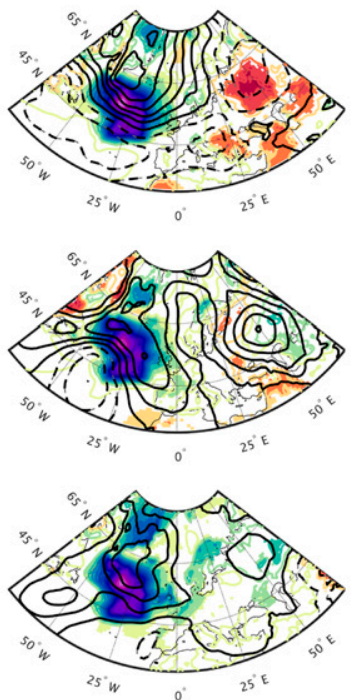

3
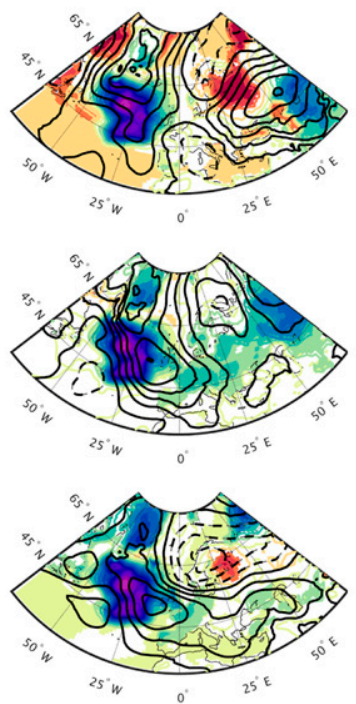

4
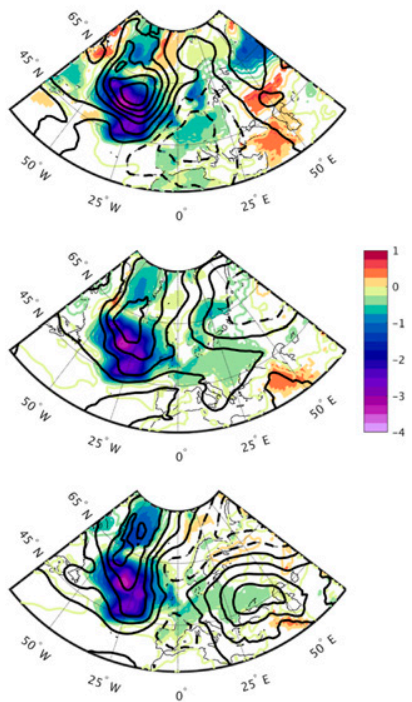

FIG. 6. DJF SOM node composite differences between the CNTRL90 and 2 KFill90 experiments for surface temperature $\left({ }^{\circ} \mathrm{C}\right.$; color filled when significant at $95 \%$ confidence level using a two-sided Student's $t$ test) and sea level pressure (hPa; contours every $0.4 \mathrm{hPa}$ with negative values dashed).

$(1,1),(1,4),(2,4)$, and $(3,4)$. In these SOM nodes, the precipitation change is collocated with increases in the DT Wind as it reaches the coastline and passing storms guided by the jet that would be exposed to warmer waters outside the NAWH prior to reaching the European coast.

1

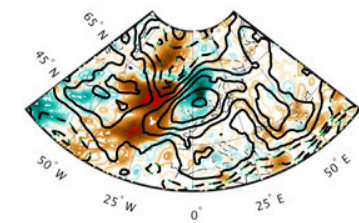

2

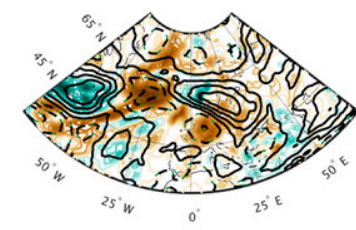

3

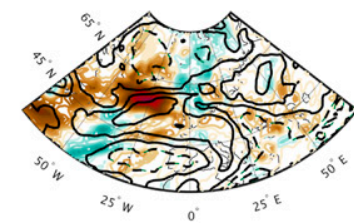

2
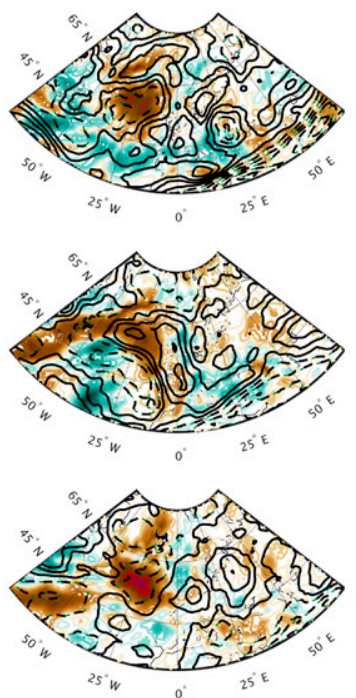

The analysis above demonstrates how both the mean daily fields associated with each map node and the relative frequency of occurrence of the SOM nodes differ as a result of the NAWH. Through Eq. (4), we can then use this information to determine which of these factors is the most important for generating the mean NAWH

FIG. 7. DJF SOM node composite differences between the CNTRL90 and 2KFill90 experiments for precipitation (mm day ${ }^{-1}$; color filled when significant at $95 \%$ confidence level as per a two-sided Student's $t$ test) and wind speed on the dynamic tropopause (m $\mathrm{s}^{-1}$; contours every $0.5 \mathrm{~m} \mathrm{~s}^{-1}$ with negative values dashed). 
CNTRL50 - 1KFill50
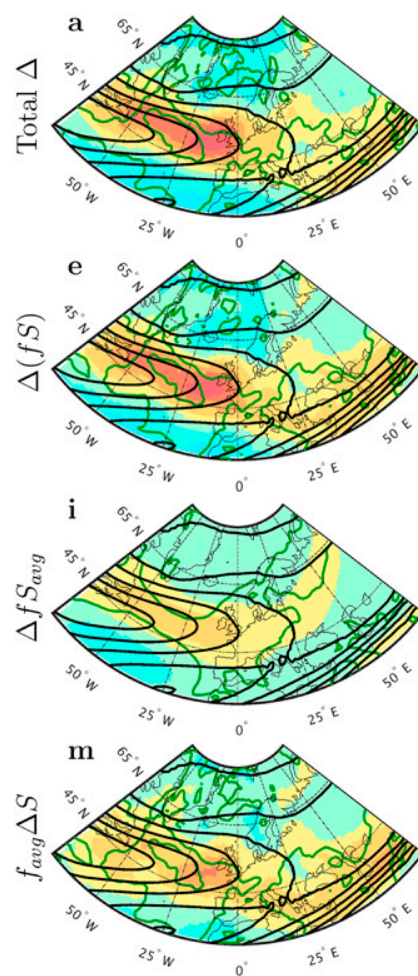

2XDeep50 - 1KFill50
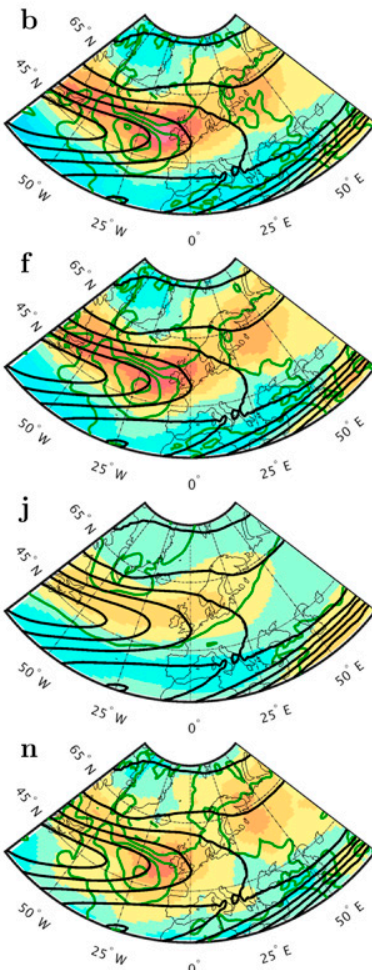

CNTRL90 - 2KFill90
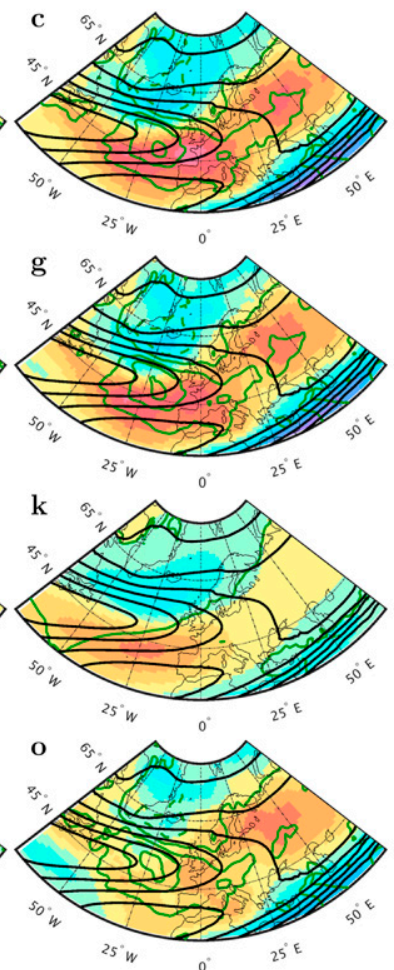

2XDeep90 - 2KFill90
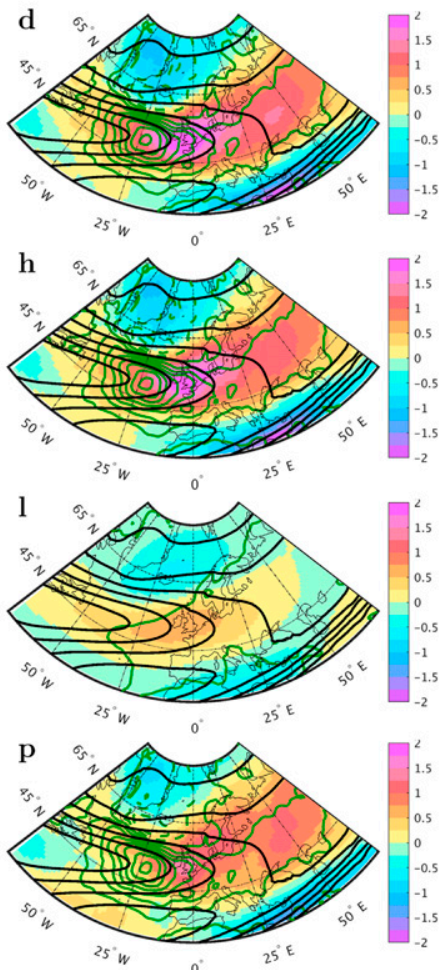

FIG. 8. (a)-(d) DJF DT Wind (color; $\mathrm{m} \mathrm{s}^{-2}$ ), $\overline{v^{\prime} T_{850}^{\prime}}$ (green contours every $0.5 \mathrm{~m}^{2} \mathrm{~s}^{-2}$; negative dashed) total difference, (e)-(h) SOM reconstructed difference $\Delta(f S)$, (i)-(l) contribution from changes in frequency to SOM reconstructed difference $\Delta f S_{\text {avg }}$, and (m)-(p) contribution from changes in node composite to SOM reconstructed difference $f_{\text {avg }} \Delta S$ between experiments (a),(e),(i),(m) CNTRL50 and 1KFill50; (b),(f),(j),(n) 2XDeep50 and 1KFill50; (c),(g),(k),(o) CNTRL90 and 2KFill90; and (d),(h),(l),(p) 2XDeep90 and 2KFill90. The DJF seasonal-mean DT Wind speed (black contours every $10 \mathrm{~m} \mathrm{~s}^{-1}$ ) is also added for reference.

impact, the frequency of occurrence versus SOM node composite. First, we verify that the reconstructed difference between experiments using the SOM nodes $\Delta(f S)$ closely resembles the total difference in mean fields (Figs. 8a-h, 9a-h, and 10a-h ). This is indeed the case, providing confidence that the decomposition of $\Delta(f S)$ into the role of frequency $\Delta f S_{\text {avg }}$ versus the SOM node composite $f_{\text {avg }} \Delta S$ will provide useful insight into the most important factors for determining the mean NAWH impact.

Results from this decomposition demonstrate that differences in both the frequency of occurrence and the SOM node composite play a role in the total differences in the North Atlantic jet between the CNTRL50 or 2XDeep50 (CNTRL90 or 2XDeep90) and 1KFill50 (2KFill90) experiments (Fig. 8). The impact of changes in SOM node frequency is similar to the total difference with a poleward enhancement of the North Atlantic jet except for the CNTRL90 - 1KFill90 case where the jet is enhanced on the equatorward side (Figs. 8i-1). These frequency differences however, are not able to explain the entire total difference. Differences in the
SOM node composite are approximately twice as large as the frequency differences and are responsible for many of the details in the response over the North Atlantic (Figs. 8m-p). There is a localized enhancement of the North Atlantic jet strength at the jet exit region concentrated over the eastern edge of the NAWH. Furthermore, changes in the SOM node composite are responsible for the notable increase in wind speed downstream over Eurasia. This is consistent with the transient eddy-mean response to the NAWH shown by Gervais et al. (2019) in the seasonal mean.

The decomposition of total response to the NAWH in $\overline{v^{\prime} T_{850}^{\prime}}$ into $\Delta f S_{\text {avg }}$ and $f_{\text {avg }} \Delta S$ shows that changes in the SOM node composite are the primary contributor to the transient eddy-mean flow response. This result is not surprising as the mechanism through which the transient eddy forced response occurs is directly related to the strength of the SST gradient associated with the NAWH. This SST gradient differs between experiments regardless of the North Atlantic jet regime. However, the impact that this forcing has on the jet itself does depend on the jet regime, as discussed above (Fig. 5). 
CNTRL50 - 1KFill50
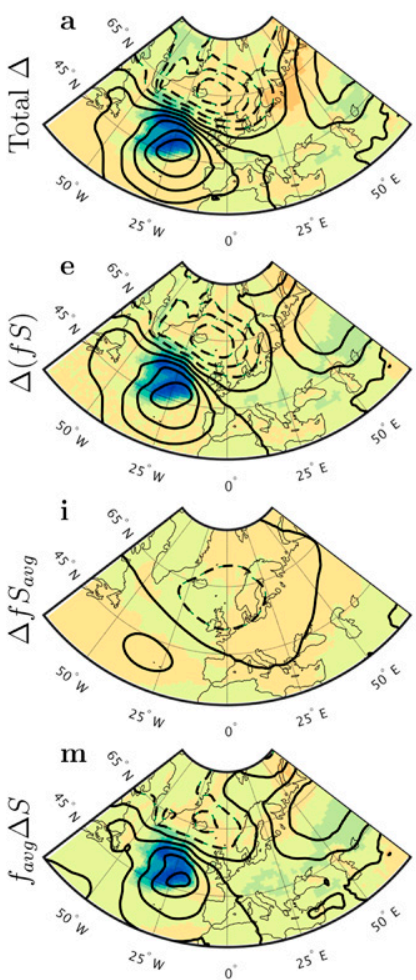

2XDeep50 - 1KFill50
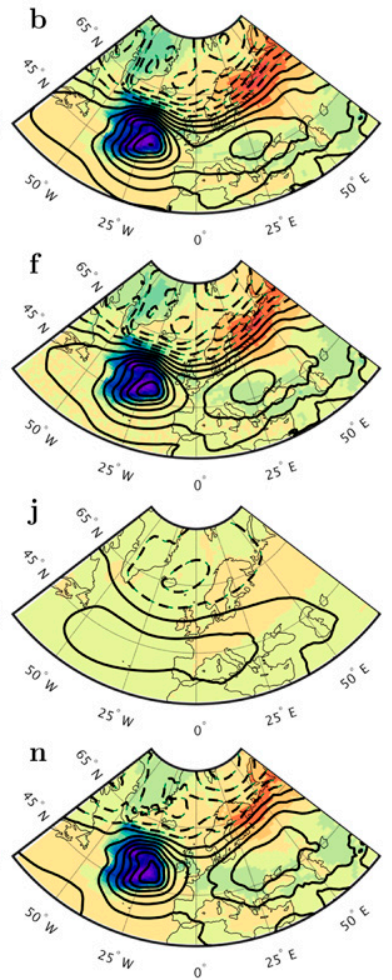

CNTRL90 - 2KFill90
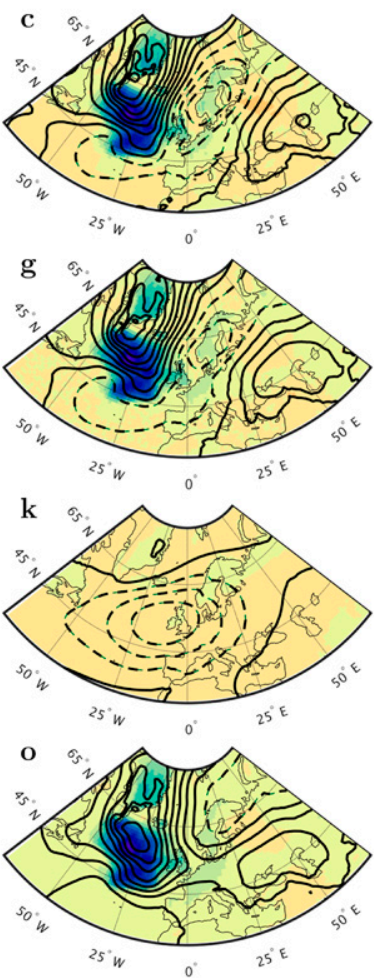

2XDeep90 - 2KFill90
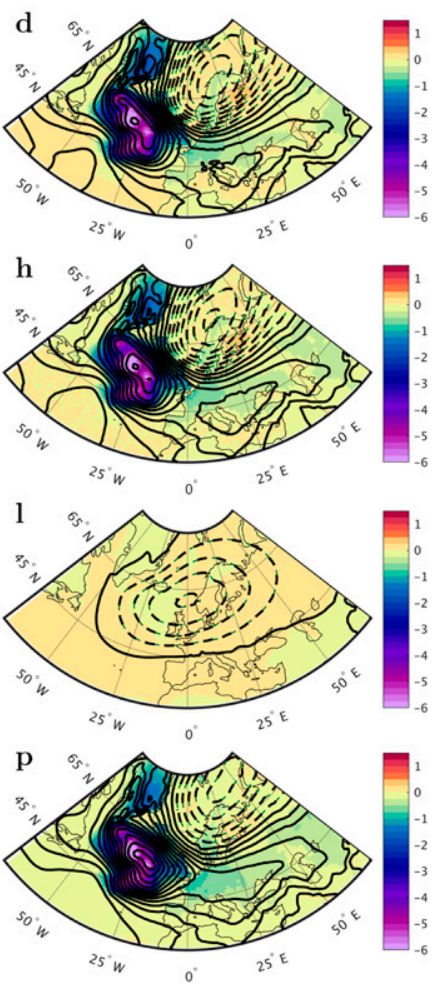

FIG. 9. DJF sea level pressure (contours every $0.2 \mathrm{hPa}$; positive, solid; negative, dashed) and surface temperature (color; $\left.{ }^{\circ} \mathrm{C}\right)$. (a)-(d) Total difference, (e)-(h) SOM reconstructed difference $\Delta(f S)$, (i)-(l) contribution from changes in frequency to SOM reconstructed difference $\Delta f S_{\text {avg }}$, and (m)-(p) contribution from changes in node composite to SOM reconstructed difference $f_{\text {avg }} \Delta S$ between experiments (a),(e),(i),(m) CNTRL50 and 1KFill50; (b),(f),(j),(n) 2XDeep50 and 1KFill50; (c),(g),(k),(o) CNTRL90 and 2KFill90; and (d),(h),(l),(p) 2XDeep90 and 2KFill90.

The total impact of the NAWH on the DT Wind is a broad increase in wind speed over Eurasia.

For SLP, the impact of frequency differences results in patterns that are consistent with an enhanced North Atlantic jet, with strengthened Icelandic low-subtropical high gradient in the 2050s and more broadly strengthened Icelandic low in the 2090s. These differences associated with changes in frequency, however, are much smaller than those associated with changes in SOM node patterns. The greatest differences in SLP occur in conjunction with the NAWH as a result of differences in SOM node composites (Figs. 9m-p), where colder SSTs lead to local decreases in TS and higher SLP. This is consistent with the linear response to the NAWH as discussed in Gervais et al. (2019). There is also an enhanced north-south dipole in SLP over Europe due to differences in SOM node composites (Fig. 9). This is consistent with the DT Wind differences from SOM node composites that are associated with the transient eddy-mean flow response to the NAWH (Fig. 5).

The total impact of the NAWH on TS over Eurasia can be understood as decreases in TS as a direct consequence of the NAWH and differences in advection at the surface due to SLP. In the CNTRL50 - 1KFill50 difference, there are some small increases in TS over Scandinavia associated with anomalous southerly flow, but the majority of Eurasia experiences reduced TS due to advection of colder temperatures from over the NAWH. In the 2XDeep50 - 1KFill50 case, there is a strong SLP dipole over Europe associated with anomalous southwesterly winds with implied anomalous warm-air advection over northern Europe where the source of maritime air is not over the NAWH, and anomalous cold-air advection over southern Europe where the source of maritime air is from the NAWH region. By the 2090s when the NAWH and its associated TS differences are greater, the SOM node composites differences are responsible for a great deal of cooling over Eurasia. Furthermore, in the 2090s there are opposing impacts of frequency and SOM node composite on the SLP differences that would reduce the southwesterly advection from the change in SOM node composite that was present in the 2050 s (Figs. 9k,1,o,p). 
CNTRL50 - 1KFill50
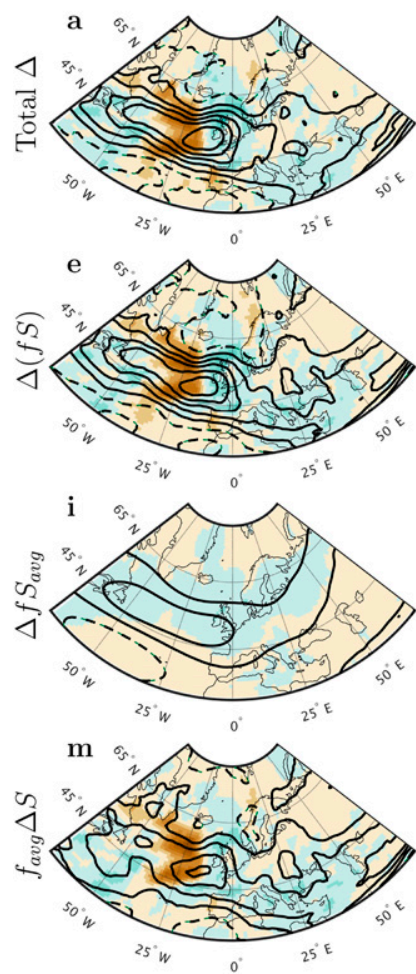

2XDeep50 - 1KFill50
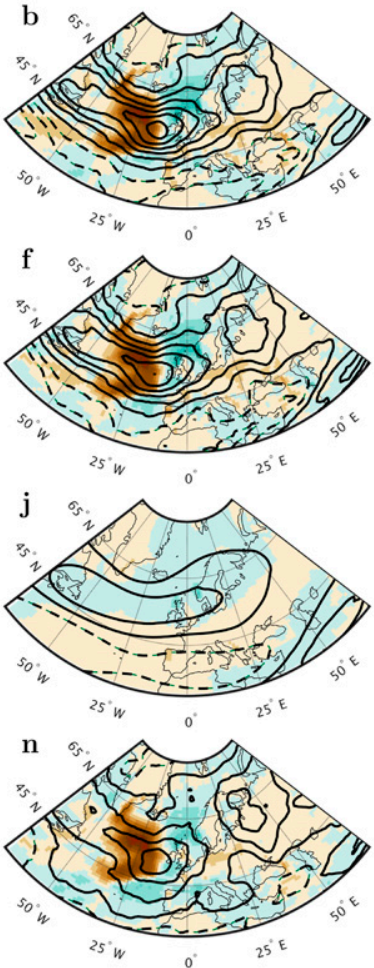

CNTRL90 - 2KFill90
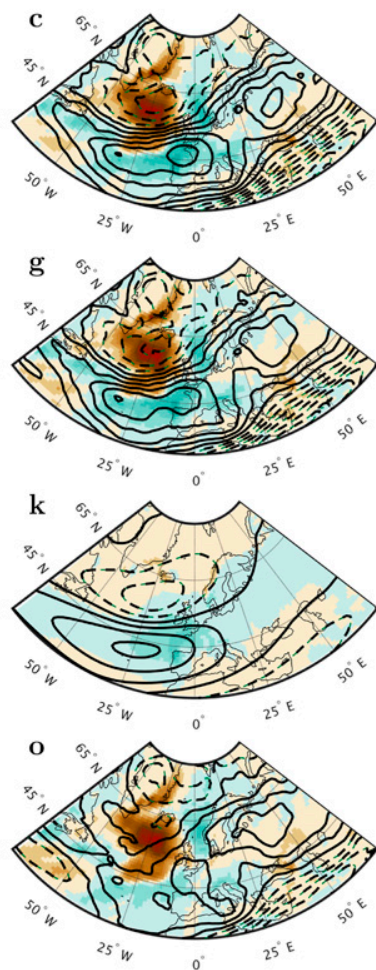

2XDeep90 - 2KFill90
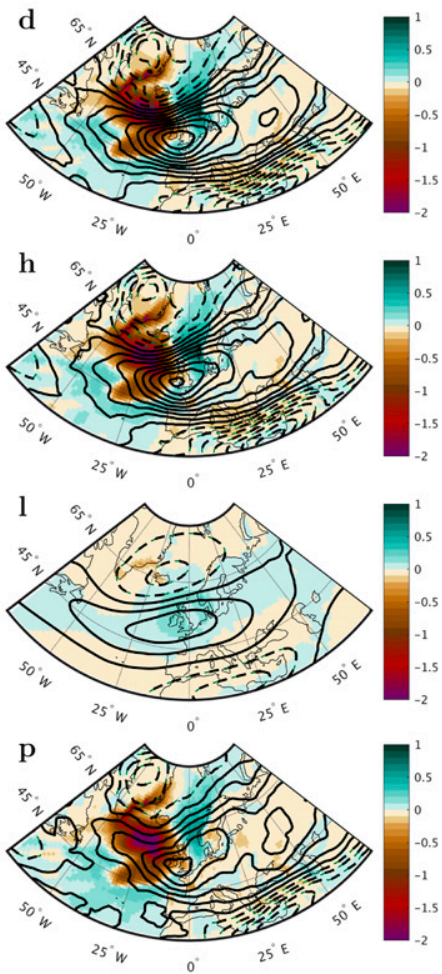

FIG. 10. DJF DT Wind (contours every $0.25 \mathrm{~m} \mathrm{~s}^{-1}$; positive, solid; negative, dashed) and total precipitation (color; $\mathrm{mm} \mathrm{day}^{-1}$ ). (a)-(d) Total difference, (e)-(h) SOM reconstructed difference $\Delta(f S)$, (i)-(l) contribution from changes in frequency to SOM reconstructed difference $\Delta f S_{\text {avg }}$, and $(\mathrm{m})-(\mathrm{p})$ contribution from changes in node composite to SOM reconstructed difference $f_{\text {avg }} \Delta S$ between experiments (a),(e),(i),(m) CNTRL50 and 1KFill50; (b),(f),(j),(n) 2XDeep50 and 1KFill50; (c),(g),(k),(o) CNTRL90 and 2KFill90; and (d),(h),(l),(p) 2XDeep90 and 2KFill90.

Since the location of the North Atlantic jet typically has a large impact on precipitation along the west coast of Europe, we would expect differences in the jet position to be associated with changes in precipitation. This impact can be seen in the role of changes in SOM node frequency as there is an increase in precipitation where elongated jets hit the European coast, particularly for the experiments in the 2090s (Figs. 10i-1). Differences in the SOM node composite, however, reveal a significant direct role of the NAWH on precipitation patterns over Europe (Figs. 10m-p). Precipitation is suppressed directly over the NAWH and enhanced over regions directly to the east and south of the NAWH. The lower SSTs associated with the NAWH reduce TS in the overlying atmosphere, which would act to stabilize the atmosphere and inhibit precipitation. As these colder air masses are subsequently transported over the warmer waters downstream of the NAWH, we would expect a reduction in the stability. This mechanism is consistent with the difference in turbulent heat flux shown in Gervais et al. (2019), where there is decreased turbulent heat flux over the warming hole due to the reduced SST and enhanced turbulent heat flux downstream as relatively colder lower-level atmospheric temperatures are advected over warmer waters.

These two impacts, frequency and SOM node composite, have very different patterns with large spatial gradients (Fig. 10). For example, differences in SOM node frequency lead to localized increases in precipitation at specific latitudes where the North Atlantic jet enhancements reach the coast. In contrast the direct impact of the NAWH is relatively constant from $45^{\circ}$ to $65^{\circ} \mathrm{N}$ and the impact on coastal precipitation is dependent instead on how far east the NAWH suppression of precipitation occurs. The direct impact of the NAWH on precipitation is highly dependent on the time period and NAWH strength. For example, in the 2050s the United Kingdom is in a region of enhanced precipitation directly east of the NAWH but as the NAWH extends eastward in the 2090s the same region experiences suppressed precipitation. The spatial incongruence of the two mechanisms and their sensitivities to time period and strength results in highly variable local impacts of the NAWH on precipitation. 


\section{Conclusions}

In this study, we use self-organizing maps to investigate changes in North Atlantic jet regimes and associated sensible weather in a series of prescribed SST modeling experiments designed to understand the impact of the NAWH. These experiments were originally produced by Gervais et al. (2019), who investigated the seasonally averaged impact of the NAWH on the atmosphere. Two dominant mechanisms for the response to the NAWH were proposed by Gervais et al. (2019), a linear response and a transient eddy-mean forced response. The linear response consists of a local cooling over the NAWH and increase in SLP as well as a baroclinic response in the geopotential height (Gervais et al. 2019). In the transient eddy-mean forced response, the enhanced SST gradient across the North Atlantic Current caused by the NAWH increases the lower tropospheric eddy heat transport (Gervais et al. 2019). This eddy energy propagates upward impacting the North Atlantic jet, forcing a poleward shift and eastward elongation of the jet in the 2050s (Gervais et al. 2019). In the 2090s the eddy energy strengthens the jet on its equatorward side in the CNTRL90 - 2KFill90 case but again forces a poleward shift and eastward elongation when the warming hole is twice deepened in the 2XDeep90 - 2KFill90 case (Gervais et al. 2019). Gervais et al. (2019) hypothesized that the strengthening of the subtropical jet as a response to greenhouse gas forcing may lead to a deposition of eddy energy into the subtropical rather than eddy-driven jet in the CNTRL90 - 2KFill90 case, more akin to the Pacific Ocean. As the NAWH strengthens in the 2XDeep90 2KFill90 case the baroclinic forcing may become sufficiently strong to allow the eddy-driven jet to become stronger than the subtropical jet, such that resulting eddy energy once again feeds the eddy-driven jet rather than the subtropical jet.

We conduct an SOM analysis applied to wind speed on the dynamic tropopause to identify the dominant North Atlantic jet regimes. We then examine the impact of the NAWH on these North Atlantic jet regimes by considering both differences between experiments in the frequency of occurrence and in the composites of daily data associated with each SOM node. The NAWH impacts the frequency of occurrence of jet regimes but more importantly the character of the jet itself in these regimes. In general, there is a strengthening of the jet over the NAWH region that is captured both in the differences in frequency of occurrence and the differences in SOM node composite. The transient eddy-mean forced response, which impacts farther downstream, is found primarily in the differences in SOM node composites between simulations. These results highlight an important factor to consider when examining changes in variability. When a dimension reduction is conducted it is important to look not only at the mode strength or frequency of occurrence but also at differences in the mode of variability itself. Although this observation is made here for the SOM methodology it would also hold true for other dimension reduction methods such as EOF or $k$-means clustering.

Previous studies have shown that the impact of transient eddy-mean flow forcing is dependent on the mean position of the North Atlantic jet (Brayshaw et al. 2008; Nakamura et al. 2004). The downstream transient eddymean forced response found here is dependent on the regime itself, occurring at different latitudes, strengths, and orientations depending on the SOM node. The sum total of these downstream enhancements is a broad increase in wind speed on the DT over Eurasia in the seasonal-mean differences in experiments. This analysis further demonstrates that the stationary surface forcing from the NAWH similarly has differing impacts on the North Atlantic jet depending on the jet regime.

Changes in SLP and TS with the development of the NAWH can be explained nearly entirely as a result of changes in the SOM node composites themselves. There are large negative TS differences over the NAWH, as expected given the imposed SSTs, and positive SLP differences over the NAWH, consistent with the linear response to these SST differences. There are also SOM node composite differences in SLP between experiments that would impact low-level advections. In general, TS is higher in locations where the node composite SLP differences have a more southerly component and vice versa. More importantly, the large negative TS differences over the NAWH lead to lower TS over Eurasia for patterns where air is advected into Europe from the subpolar gyre. These differences are dependent on the jet regime with larger differences in SLP and TS within specific regimes than in the seasonal average. This implies that the NAWH has a larger impact on daily TS than can be seen in the seasonal average.

The interaction of the North Atlantic jet with the west coast of Europe is important for determining mean precipitation in these regions. As such, we would expect that changes in North Atlantic jet regimes would be important for European precipitation. In the 2090s there is a notable impact of the change in North Atlantic jet regimes with the mean elongation of the North Atlantic jet associated with enhanced precipitation where the jet interacts with the coast. However, the dominant impact of the NAWH on precipitation is occurring through suppression directly over the NAWH and enhancement on the downstream edges of the NAWH. 
We hypothesize that this is the result of changes in stability. Surface temperatures are cooled over the NAWH, leading to enhanced stability, and these colder air masses are then transported over warmer water downstream of the NAWH leading to reduced stability. This mechanism is very localized and sensitive to the warming hole strength, yet it can have a notable impact on local precipitation in coastal Europe.

The results presented in this study show that the NAWH can have a notable impact on sensible weather over Europe. These impacts are dependent on the time period, strength of the NAWH, and North Atlantic jet regime. This study focuses solely on the NAWH within the LENS experiment; however, there is a wide range in the location and strength of NAWH developments across the suite of CMIP5 models (Menary and Wood 2018). Given the sensitivity of the response to the NAWH on the location and strength, these factors may be a source of uncertainty in the future projection of changes in European sensible weather.

Acknowledgments. This research was supported by NSF Grant AGS-1303542. In this work, Y. Kushnir was supported by NSF Award AGS-1734760. The CESM project is supported by the Office of Science (BER) of the U.S. Department of Energy and the National Science Foundation. This research was enabled by CISL compute and storage resources. Bluefire, a 4064processor IBM Power6 resource with a peak of 77 teraflops, provided more than 7.5 million computing hours, the GLADE high-speed disk resources provided 0.4 petabytes of dedicated disk, and CISL's 12-PB HPSS archive provided over 1 petabyte of storage in support of this research project. Additional computations for this research were conducted with the Pennsylvania State University's Institute for CyberScience Advanced CyberInfrastructure (ICS-ACI). This content is solely the responsibility of the authors and does not necessarily represent the views of the Institute for CyberScience.

\section{REFERENCES}

Brayshaw, D. J., B. J. Hoskins, and M. Blackburn, 2008: The stormtrack response to idealized SST perturbations in an aquaplanet GCM. J. Atmos. Sci., 65, 2842-2860, https://doi.org/ 10.1175/2008JAS2657.1.

,-- , and,- 2011 : The basic ingredients of the North Atlantic storm track. Part II: Sea surface temperatures. J. Atmos. Sci., 68, 1784-1805, https://doi.org/10.1175/2011JAS3674.1.

Cassano, E. N., A. H. Lynch, J. J. Cassano, and M. R. Koslow, 2006: Classification of synoptic patterns in the western Arctic associated with extreme events at Barrow, Alaska, USA. Climate Res., 30, 83-97, https://doi.org/10.3354/cr030083.

Cassano, J. J., P. Uotila, and A. Lynch, 2006: Changes in synoptic weather patterns in the polar regions in the twentieth and twenty-first centuries, Part 1: Arctic. Int. J. Climatol., 26, 10271049, https://doi.org/10.1002/joc.1306.

Cavazos, T., 2000: Using self-organizing maps to investigate extreme climate events: An application to wintertime precipitation in the Balkans. J. Climate, 13, 1718-1732, https://doi.org/ 10.1175/1520-0442(2000)013<1718:USOMTI>2.0.CO;2.

Ciasto, L., C. Li, J. Wettstein, and N. Kvamsto, 2016: North Atlantic storm-track sensitivity to projected sea surface temperature: Local versus remote influences. J. Climate, 29, 69736991, https://doi.org/10.1175/JCLI-D-15-0860.1.

Dai, A., I. Y. Fung, and A. D. Del Genio, 1997: Surface observed global land precipitation variations during 1900-88. J. Climate, 10, 2943-2962, https://doi.org/10.1175/1520-0442(1997)010<2943: SOGLPV $>2.0 . \mathrm{CO} ; 2$.

Delworth, T. L., and F. Zeng, 2016: The impact of the North Atlantic Oscillation on climate through its influence on the Atlantic meridional overturning circulation. J. Climate, 29, 941-962, https://doi.org/10.1175/JCLI-D-15-0396.1.

Deser, C., G. Magnusdottir, R. Saravanan, and A. Phillips, 2004: The effects of North Atlantic SST and sea ice anomalies on the winter circulation in CCM3. Part II: Direct and indirect components of the response. J. Climate, 17, 877-889, https:// doi.org/10.1175/1520-0442(2004)017<0877:TEONAS > 2.0.CO;2.

Drijfhout, S., G. J. van Oldenborgh, and A. Cimatoribus, 2012: Is a decline of AMOC causing the warming hole above the North Atlantic in observed and modeled warming patterns? J. Climate, 25, 8373-8379, https://doi.org/10.1175/JCLI-D-1200490.1 .

Gervais, M., E. Atallah, J. R. Gyakum, and L. B. Tremblay, 2016: Arctic air masses in a warming world. J. Climate, 29, 23592373, https://doi.org/10.1175/JCLI-D-15-0499.1.

_ J. Shaman, and Y. Kushnir, 2018: Mechanisms governing the development of the North Atlantic warming hole in the CESM-LE future climate simulations. J. Climate, 31, 59275946, https://doi.org/10.1175/JCLI-D-17-0635.1.

,-- , and -2019 : Impacts of the North Atlantic warming hole in future climate projections: Mean atmospheric circulation and the North Atlantic jet. J. Climate, 32, 2673-2689, https://doi.org/10.1175/JCLI-D-18-0647.1.

Hall, N. M., H. Lin, and J. Derome, 2001: The extratropical signal generated by a midlatitude SST anomaly. Part II: Influence on seasonal forecasts. J. Climate, 14, 2696-2709, https://doi.org/10.1175/1520-0442(2001)014<2696:TESGBA> 2.0.CO;2.

Harvey, B. J., L. C. Shaffrey, and T. J. Woollings, 2015: Deconstructing the climate change response of the Northern Hemisphere wintertime storm tracks. Climate Dyn., 45, 28472860, https://doi.org/10.1007/s00382-015-2510-8.

Hendon, H. H., and D. L. Hartmann, 1982: Stationary waves on a sphere: Sensitivity to thermal feedback. J. Atmos. Sci., 39, 1906-1920, https://doi.org/10.1175/1520-0469(1982)039<1906: SWOASS $>2.0$.CO;2.

Hewitson, B. C., and R. G. Crane, 2002: Self-organizing maps: Applications to synoptic climatology. Climate Res., 22, 13-26, https://doi.org/10.3354/cr022013.

Hoskins, B. J., and D. J. Karoly, 1981: The steady linear response of a spherical atmosphere to thermal and orographic forcing. J. Atmos. Sci., 38, 1179-1196, https://doi.org/10.1175/15200469(1981)038<1179:TSLROA > 2.0.CO;2.

Hurrell, J. W., 1995: Decadal trends in the North Atlantic Oscillation: Regional temperatures and precipitation. Science, 269, 676-679, https://doi.org/10.1126/science.269.5224.676. 
—, Y. Kushnir, G. Ottersen, and M. Visbeck, 2003: The North Atlantic Oscillation: Climatic Significance and Environmental Impact. Geophys. Monogr., Vol. 134, Amer. Geophys. Union, 279 pp.

_ , and Coauthors, 2013: The Community Earth System Model: A framework for collaborative research. Bull. Amer. Meteor. Soc., 94, 1339-1360, https://doi.org/10.1175/BAMS-D-12-00121.1.

Inatsu, M., H. Mukougawa, and S.-P. Xie, 2003: Atmospheric response to zonal variations in midlatitude SST: Transient and stationary eddies and their feedback. J. Climate, 16, 3314-3329, https://doi.org/10.1175/1520-0442(2003)016<3314: ARTZVI>2.0.CO;2.

Johnson, N. C., S. B. Feldstein, and B. Tremblay, 2008: The continuum of Northern Hemisphere teleconnection patterns and a description of the NAO shift with the use of self-organizing maps. J. Climate, 21, 6354-6371, https://doi.org/10.1175/ 2008JCLI2380.1.

Kay, J. E., and Coauthors, 2015: The Community Earth System Model (CESM) large ensemble project: A community resource for studying climate change in the presence of internal climate variability. Bull. Amer. Meteor. Soc., 96, 1333-1349, https://doi.org/10.1175/BAMS-D-13-00255.1.

Kohonen, T., 2001: Self-Organizing Maps. 3rd ed. Springer, 528 pp.

Kushnir, Y., W. Robinson, I. Bladé, N. M. J. Hall, S. Peng, and R. Sutton, 2002: Atmospheric GCM response to extratropical SST anomalies: Synthesis and evaluation. J. Climate, 15, 22332256, https://doi.org/10.1175/1520-0442(2002)015<2233:AGRTES> 2.0.CO;2

Liu, Y., R. H. Weisberg, and C. N. K. Mooers, 2006: Performance evaluation of the self-organizing map for feature extraction. J. Geophys. Res., 111, C05018, https://doi.org/10.1029/ $2005 \mathrm{JC} 003117$.

Magnusdottir, G., C. Deser, and R. Saravanan, 2004: The effects of North Atlantic SST and sea ice anomalies on the winter circulation in CCM3. Part I: Main features and storm track characteristics of the response. J. Climate, 17, 857-876, https:// doi.org/10.1175/1520-0442(2004)017<0857:TEONAS $>$ 2.0. $\mathrm{CO} ; 2$.

Menary, M. B., and R. A. Wood, 2018: An anatomy of the projected North Atlantic warming hole in CMIP5 models. Climate Dyn., 50, 3063-3080, https://doi.org/10.1007/s00382-017-3793-8.

Nakamura, H., T. Sampe, Y. Tanimoto, and A. Shimpo, 2004: Observed associations among storm tracks, jet streams and midlatitude oceanic fronts. Earth's Climate: The OceanAtmosphere Interaction, Geophys. Monogr., Vol. 147, Amer. Geophys. Union, 329-345, https://doi.org/10.1029/147GM18.

Palmer, T. N., and Z. Sun, 1985: A modelling and observational study of the relationship between sea surface temperature in the north-west Atlantic and the atmospheric general circulation. Quart. J. Roy. Meteor. Soc., 111, 947-975, https://doi.org/ 10.1002/qj.49711147003.

Peings, Y., G. Simpkins, and G. Magnusdottir, 2016: Multidecadal fluctuations of the North Atlantic Ocean and feedback on the winter climate in CMIP5 control simulations. J. Geophys. Res. Atmos., 121, 2571-2592, https://doi.org/10.1002/2015JD024107.
Peng, S., and J. S. Whitaker, 1999: Mechanisms determining the atmospheric response to midlatitude SST anomalies. J. Climate, 12, 1393-1408, https://doi.org/10.1175/1520-0442(1999)012<1393: MDTART $>2.0 . \mathrm{CO} ; 2$.

, and W. A. Robinson, 2001: Relationships between atmospheric internal variability and the responses to an extratropical SST anomaly. J. Climate, 14, 2943-2959, https://doi.org/10.1175/ 1520-0442(2001)014<2943:RBAIVA > 2.0.CO;2.

Rahmstorf, S., J. E. Box, G. Feulner, M. E. Mann, A. Robinson, S. Rutherford, and E. J. Schaffernicht, 2015: Exceptional twentieth-century slowdown in Atlantic Ocean overturning circulation. Nat. Climate Change, 5, 475-480, https://doi.org/ 10.1038/nclimate2554.

Reusch, D. B., R. B. Alley, and B. C. Hewitson, 2005: Relative performance of self-organizing maps and principal component analysis in pattern extraction from synthetic climatological data. Polar Geogr., 29, 188-212, https://doi.org/10.1080/ 789610199.

_ - — and - 2007: North Atlantic climate variability from a self-organizing map perspective. J. Geophys. Res., 112, D02104, https://doi.org/10.1029/2006JD007460.

Sammon, J., 1969: A nonlinear mapping for data structure analysis. IEEE Trans. Comput., 18, 401-409, https://doi.org/10.1109/TC.1969.222678.

Schuenemann, K. C., and J. J. Cassano, 2009: Changes in synoptic weather patterns and Greenland precipitation in the 20th and 21st centuries: 1. Evaluation of late 20th century simulations from IPCC models. J. Geophys. Res., 114, D20113, https:// doi.org/10.1029/2009JD011705.

, and - 2010: Changes in synoptic weather patterns and Greenland precipitation in the 20th and 21st centuries: 2 . Analysis of 21 st century atmospheric changes using selforganizing maps. J. Geophys. Res., 115, D05108, https://doi.org/ 10.1029/2009JD011706

Ting, M., and S. Peng, 1995: Dynamics of the early and middle winter atmospheric responses to the northwest Atlantic SST anomalies. J. Climate, 8, 2239-2254, https://doi.org/10.1175/ 1520-0442(1995)008<2239:DOTEAM >2.0.CO;2.

Vesanto, J., J. Himberg, E. Alhoniemi, and J. Parhankangas, 2000: SOM toolbox for Matlab 5. Tech. Rep. A57, Helsinki University of Technology, $59 \mathrm{pp}$.

Wilson, C., B. Sinha, and R. G. Williams, 2009: The effect of ocean dynamics and orography on atmospheric storm tracks. J. Climate, 22, 3689-3702, https://doi.org/10.1175/2009JCLI2651.1.

Winton, M., S. M. Griffies, B. L. Samuels, J. L. Sarmiento, and T. L. Frölicher, 2013: Connecting changing ocean circulation with changing climate. J. Climate, 26, 2268-2278, https://doi.org/ 10.1175/JCLI-D-12-00296.1.

Woollings, T., J. Gregory, J. Pinto, M. Reyers, and D. Brayshaw, 2012: Response of the North Atlantic storm track to climate change shaped by ocean-atmosphere coupling. Nat. Geosci., 5, 313-317, https://doi.org/10.1038/ngeo1438.

, and Coauthors, 2018: Daily to decadal modulation of jet variability. J. Climate, 31, 1297-1314, https://doi.org/10.1175/ JCLI-D-17-0286.1. 